\title{
Review Article \\ Do PPAR-Gamma Agonists Have a Future in Parkinson's Disease Therapy?
}

\author{
Anna R. Carta, Augusta Pisanu, and Ezio Carboni \\ Department of Toxicology, University of Cagliari, Via Ospedale 72, 09124 Cagliari, Italy \\ Correspondence should be addressed to Anna R. Carta, acarta@unica.it
}

Received 2 December 2010; Accepted 27 January 2011

Academic Editor: Fernando Pitossi

Copyright () 2011 Anna R. Carta et al. This is an open access article distributed under the Creative Commons Attribution License, which permits unrestricted use, distribution, and reproduction in any medium, provided the original work is properly cited.

Thiazolidinediones (TZDs) are peroxisome proliferator-activated receptor (PPAR)- $\gamma$ agonists commonly used as insulinsensitizing drugs for the treatment of type 2 diabetes. In the last decade, PPAR- $\gamma$ agonists have received increasing attention for their neuroprotective properties displayed in a variety of neurodegenerative diseases, including Parkinson's disease (PD), likely related to the anti-infammatory activity of these compounds. Recent studies indicate that neuroinflammation, specifically reactive microglia, plays important roles in PD pathogenesis. Moreover, after the discovery of infiltrating activated Limphocytes in the substantia nigra (SN) of PD patients, most recent research supports a role of immune-mediated mechanisms in the pathological process leading to chronic neuroinflammation and dopaminergic degeneration. PPAR- $\gamma$ are highly expressed in cells of both central and peripheral immune systems, playing a pivotal role in microglial activation as well as in monocytes and $\mathrm{T}$ cells differentiation, in which they act as key regulators of immune responses. Here, we review preclinical evidences of PPAR- $\gamma$-induced neuroprotection in experimental PD models and highlight relative anti-inflammatory mechanisms involving either central or peripheral immunomodulatory activity. Specific targeting of immune functions contributing to neuroinflammation either directly (central) or indirectly (peripheral) may represent a novel therapeutic approach for disease modifying therapies in PD.

\section{Introduction}

Thiazolidinediones (TZDs), including rosiglitazone and pioglitazone, are currently in clinical use as insulin-sensitizing agents for the treatment of type 2 diabetes [1]. These drugs were originally designed as agonists of the peroxisome proliferator-activated receptor- $\gamma$ (PPAR- $\gamma$ ), belonging to the hormone nuclear receptor superfamily. PPAR- $\gamma$ mediates liganddependent transcription and is activated, beside synthetic agonists TZD, by naturally occurring compounds, such as longchain fatty acids and the prostaglandin 15-deoxy $\Delta$, prostaglandin J2 (15d-PGJ2), but also few nonsteroidal antiinflammatory drugs (NSAIDs), as ibuprofen, fenoprofen, and indomethacin [2-6]. In the last decade, the neuroprotective properties of PPAR- $\gamma$ agonists have received increasing attention and researchers have provided a multitude of evidences in preclinical models of a variety of acute and chronic neurodegenerative conditions, including PD, Alzheimer's disease, cerebral ischemia, amyotrophic lateral sclerosis, and spinal cord injury. These evidences have led to rosiglitazone evaluation in phase II and III clinical trials in patients with Alzheimer's disease and ischemia [7-15].

\section{Safety Concerns of TZDs Therapy}

TZDs include troglitazone, which was removed from the market because of hepatotoxicity, and two currently available agents, rosiglitazone (Avandia, GlaxoSmithKline) and pioglitazone (Actos, Takeda). Rosiglitazone was introduced into the market in 1999 and has been widely used as monotherapy or in fixed-dose combinations with either metformin (Avandamet, GlaxoSmithKline) or glimepiride (Avandaryl, GlaxoSmithKline).

TZDs safety has been constantly monitored, mostly for the cardiovascular risks in diabetic patients, since more than $65 \%$ of deaths in patients with diabetes are from cardiovascular causes [16]. Multicentre studies aimed at assessing rosiglitazone-associated risks for cardiovascular diseases in diabetes have been recently completed [17-21]. The most reliable and informative studies are the ADOPT [19], 
DREAM [21] and the recently completed RECORD studies for rosiglitazone [18], and the PROactive study for pioglitazone [22]. Few meta-analysis have also investigated the cardiovascular risks of TZDs in diabetes, leading however, to controversial conclusion [16, 23, 24]. Both rosiglitazone and pioglitazone have been associated dose-dependently with fluid retention and accumulation, increased body weight, and increased LDL cholesterol concentration, that may indirectly lead to heart failure in diabetic patients $[18,19$, 25]. On the other hand, there is no evidence of TZDs direct cardiotoxicity. Moreover, TZDs have been shown to improve some cardiovascular risk markers associated with diabetes, as insulin sensitivity, blood pressure, and coagulation factors $[26,27]$. Beside cardiovascular complications, in diabetic patients rosiglitazone has been associated with an increased risk of bone fractures, particularly in woman [18].

Given the intrinsic risk of cardiovascular complications in diabetic patients, concerns on TZDs safety have recently led to rosiglitazone withdrawal from the market in Europe and its inclusion in a restricted access program in the US as hypoglycemic drug (FDA safety Information). (http://www .fda.gov/downloads/Drugs/DrugSafety/PostmarketDrugSafetyInformationforPatientsandProviders/UCM226959.pdf).

In contrast, no data are available up to date for nondiabetic or PD patients. It should be also noticed that rosiglitazone is currently in phase III clinical trial on Alzheimer disease, as well as several other diseases, including ischemia, cancer, and asthma (NCT00348140, NCT00265148, NCT00405015, NCT00369174, and NCT00119496). Overall, available data on TZDs safety, while not voiding studies for use of these drugs in other chronic diseases as PD, prompt for search of new PPAR- $\gamma$ agonists with increased CNS permeability, which would likely permit to use lower doses regimens thus reducing peripheral side-effects risks.

\section{Cellular Distribution of PPAR-Gamma}

PPAR- $\gamma$ has been demonstrated in a large variety of cells. The highest level of expression is shown by adipose tissue and by cells of the peripheral and central immune systems $[6,28-32]$. This distribution pattern reflects the actions of PPAR- $\gamma$ in regulating glucose and lipid metabolism, in promoting lipid storage and adipocyte differentiation $[6,33,34]$. Moreover, peripheral PPAR- $\gamma$ is involved in the modulation of inflammatory cytokines production by monocyte/macrophages and endothelial cells, as well as in immune cell differentiation and function $[3,35]$. In the central nervous system (CNS), PPAR- $\gamma$ is expressed in several cell types including microglia, neurons, astrocytes, and oligodendrocytes [2,36, 37]. Microglial cells constitutively express PPAR- $\gamma$, its levels being tightly regulated and dependent on microglial functional state [38]. In neurons, PPAR$\gamma$ immunoreactivity appears mainly as a nuclear labeling although sometimes cytoplasmic staining is detectable in some cortical neuron $[37,39]$. High levels of PPAR- $\gamma$ have been found in the piriform cortex and olfactory tubercle, in the basal ganglia, in rhomboid, centromedial, and parafascicular thalamic nuclei, in the reticular formation, and in the stellate cells of cerebellar cortex [37]. The abundance of PPAR- $\gamma$ in basal ganglia regions, and areas expressing dopamine receptors supports the increasing interest for PPAR $-\gamma$ agonists in PD management. PPAR- $\gamma$ expression in astrocytes results in some way inhomogeneous, since in white matter structures PPAR- $\gamma$ positive and negative astrocytes were found within the same area, albeit they have been found homogeneously expressed in adult cultured cortical astrocytes $[36,37]$.

\section{PPAR-Gamma Agonists in Preclinical Models of PD}

PD is a neurodegenerative disorder characterized by the progressive death of dopaminergic neurons of the substantia nigra pars compacta $(\mathrm{SNc})$, resulting in a progressive deficiency of nigrostriatal dopamine transmission. Clinical symptoms of PD generally manifest when striatal dopamine (DA) levels are largely reduced and most nigral neurons are lost. The pathological development underlying neurodegeneration, at the time the diagnosis is made, is characterized by an unbalanced neuronal network due to a complex scenario of malfunctioning cellular components, including oxidative stress, impaired protein disposal systems, and chronic neuroinflammation [40].

Animal models of PD have been fruitfully used for contributing to a better knowledge of major mechanisms involved in this disease and to explore new potential therapies. Animal models of PD should possess the highest number of features of human PD (face validity), underlying neuropathology should evolve as much as possible as PD and should respond to treatments in a manner comparable to human PD (predictive validity). Lastly, they should also reproduce the complex scenario of multiple interaction between neuronal elements and surrounding cells (construct validity). Among cells that play a relevant role in this scenario, microglia, astrocytes, and endothelial cells are major players.

1-methyl-4-phenyl-1,2,3,6-tetrahydropyridine (MPTP) administration has been widely used in animals to reproduce PD symptoms, and, among animals, primates and mice have been used, the latter being easy to handle and affordable. Among the different MPTP-based models used so far, the acute MPTP, the subacute MPTP and the chronic MPTP paradigms have provided compelling results for a role of PPAR- $\gamma$ in neuroinflammation and neurodegeneration in PD $[8,9,41]$. In this section, evidences for PPAR- $\gamma$-mediated neuroprotection in different MPTP-based PD models are summarized.

4.1. Acute MPTP. The acute MPTP model, consisting of male C57BL/6 mice that received four intraperitoneal administration of MPTP- $\mathrm{HCl}(15 \mathrm{mg} / \mathrm{kg})$ at 2-h intervals in one day has been used by Breidert and colleagues [8]. This treatment determined a significant reduction of tyrosine hydroxylase ( $\mathrm{TH}$ )-positive cells in the $\mathrm{SNc}$ at 2, 5, and 8 days 


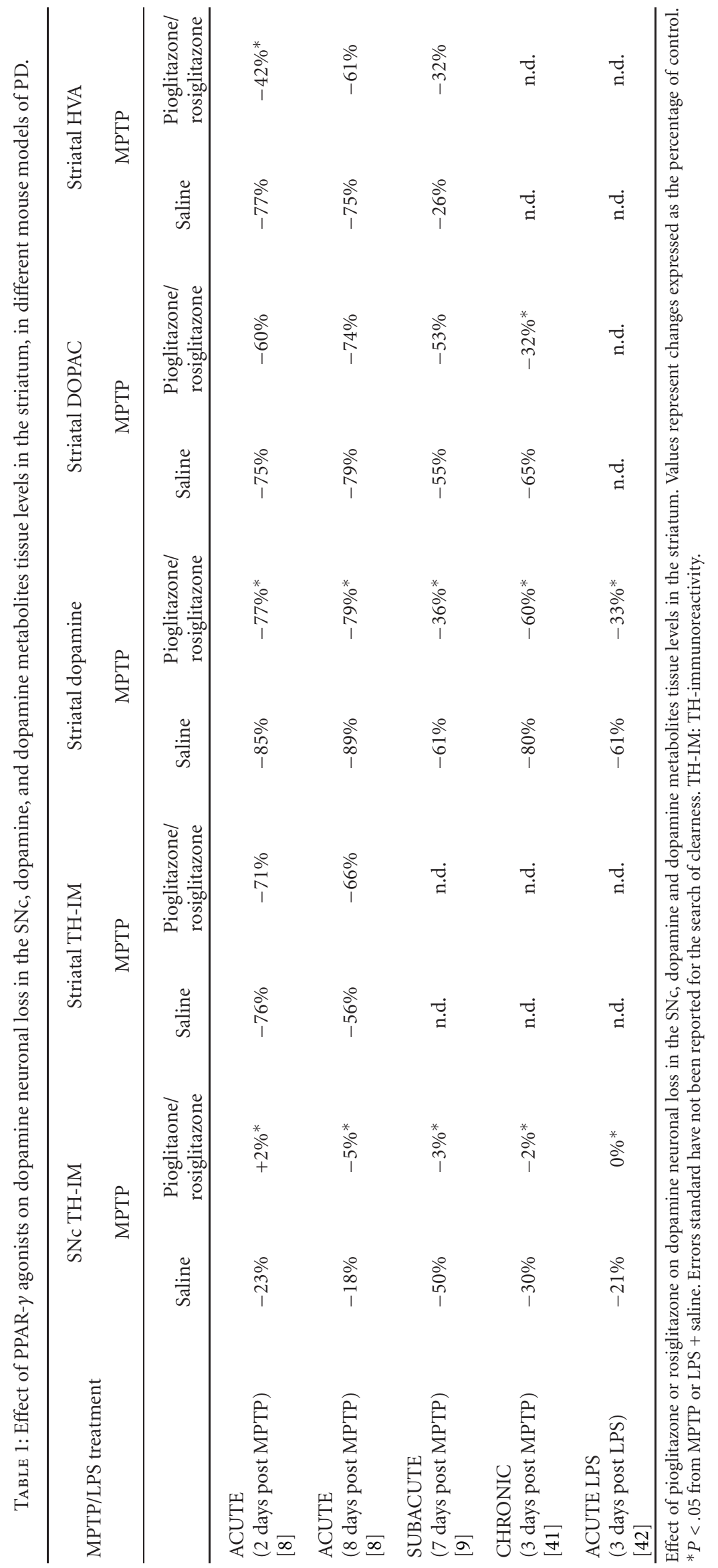


after the last neurotoxin injection (Table 1). $20 \mathrm{mg} / \mathrm{kg} /$ day of pioglitazone, administered in rodent chows, prevented the dopaminergic cell loss in the $\mathrm{SNc}$ and attenuated the MPTP-induced glial activation. Furthermore, whereas TH immunoreactivity in the striatum was decreased in MPTPtreated mice as compared to controls, pioglitazone treatment did not significantly prevent striatal $\mathrm{TH}$ immunoreactivity loss, suggesting that the neuroprotective mechanism of this drug at dopamine cell-body level was somehow selective (Table 1). However, MPTP-induced decline of striatal tissue content of DA, DOPAC, and HVA was partially but significantly prevented by pioglitazone (Table 1). Overall, although the authors hypothesized that a higher energy demand of striatal nerve terminals could make the striatum more vulnerable to MPTP toxicity, masking the ability of pioglitazone to show a protective effect, it remains to be investigated why dopamine terminals were less protected than dopamine cell bodies.

4.2. Subacute MPTP. Dehmer and colleagues used the subacute MPTP model in C57BL/6 mice, consisting of $30 \mathrm{mg} / \mathrm{kg}$ i.p. MPTP at $24 \mathrm{~h}$ intervals for 2 or 5 days [9]. $20 \mathrm{mg} / \mathrm{kg} /$ day pioglitazone was administered in rodent chows, starting 4 days before MPTP injection. Animal were killed one week after the last MPTP administration. By using this protocol, the authors showed that subacute MPTP administration caused $50 \%$ loss of $\mathrm{TH}$ positive neurons in the $\mathrm{SNc}$, whereas pioglitazone administration completely protected the SNc from cell loss. In addition, pioglitazone treatment partially prevented MPTP-induced striatal DA decline, whereas reduction of DOPAC and HVA were not affected (Table 1).

4.3. Chronic MPTP. In the study by Schintu and colleagues, the authors used the chronic MPTP plus probenecid (MPTPp) mouse model of progressive PD to assess the therapeutic efficacy of rosiglitazone on neurodegeneration, neuroinflammation and behavioural impairment [15]. In this study C57Bl/6J mice received 10 doses of MPTP $(25 \mathrm{mg} / \mathrm{kg}$ i.p.) and probenecid $(250 \mathrm{mg} / \mathrm{kg}$ i.p. $)$ administered twice a week for 5 weeks. Rosiglitazone $(10 \mathrm{mg} / \mathrm{kg}$ i.p.) was administered daily until sacrifice, three days after last neurotoxin administration. The efficacy of rosiglitazone in preventing the deleterious effect of chronic MPTPp was assessed in a wide variety of behavioural and biochemical tests. In particular, mice chronically treated with MPTPp displayed typical features of PD, including progressive impairment of motor and olfactory functions (Figure 1) associated with partial loss of TH-positive neurons in the SNc (Table 1), decrease of DA and DOPAC content and dynorphin mRNA levels in the striatum, and intense microglial and astroglial response in the $\mathrm{SNc}$ and striatum. Chronic rosiglitazone administered in association with MPTPp, completely prevented motor and olfactory dysfunctions and loss of TH-positive cells in the SNc (Figure 1 and Table 1). In the striatum, MPTPpinduced loss of striatal dopamine was partially prevented by rosiglitazone, whereas decrease in DOPAC content and dynorphin were fully counteracted. Therefore, these results clearly showed that DA neurons preservation by the PPAR$\gamma$ agonist was associated with preservation of motor functions. Moreover, while emphasizing the sensibility of striatal DA terminals to MPTPp chronic treatment, this study interrelated rosiglitazone-mediated preservation of motor functions to level of DA damage in the striatum, somehow reproducing a crucial feature of $\mathrm{PD}$, where the appearance of behavioural deficits is strictly correlated with a threshold damage of striatal DA transmission.

4.4. Intrastriatal LPS. Hunter and coworkers tested the neuroprotective potential of the anti-inflammatory drug celecoxib, an inhibitor of cyclo-oxygenase-2 (COX-2) and the PPAR- $\gamma$ agonist pioglitazone against the neuronal damage induced by intrastriatal injection of lipopolysaccharide (LPS) in rats [42]. Celecoxib (administered twice a day at $10 \mathrm{mg} / \mathrm{kg}$, for four days before LPS injection) and pioglitazone $(20 \mathrm{mg} / \mathrm{kg}$ daily for four days before LPS injection) prevented the loss of dopaminergic neurons and striatal DA decline, as observed 3 day after LPS injection. In addition, Celecoxib and pioglitazone decreased the neuroinflammatory reaction and restored mitochondrial function, providing a mechanism of neuroprotection [43].

\section{PPAR- $\gamma$ Agonists and Central Inflammation in PD}

5.1. Microglia. Recent studies indicate that neuroinflammation and microglia activation play important roles in PD pathogenesis, as suggested by the high levels of reactive microglia found in the SNc of PD patients [44-46]. Microglia are the resident immune-competent cells of the CNS, commonly described as the CNS equivalent of macrophages, having a role in monitoring the brain for immune insults and invading pathogens [47-51]. It has been recently reported that primitive myeloid precursors give rise, before embryonic day 8 , to microglia residing in the adult CNS in the steady state [52]. Recent interpretation of this cell population suggests that microglia do not constitute a uniform cell population but rather comprise a family of cells with different phenotypes, some of which are beneficial and others detrimental and toxic for the CNS [53]. In the healthy brain, the majority of microglia are in the resting state, with rod-shaped soma ramified and tiny processes. In this state, microglia show low expression of molecules associated with macrophage functions [53]. Upon activating stimuli from extracellular environment, as damaged neurons, endotoxins, cytokines, and aberrant proteins, microglia become reactive, progressively switching to different stages of activity, characterized by morphological and phenotypic changes. Assumption of macrophage functions allow them to respond to pathological insults $[45,49,54,55]$. Morphologically, at least three activity stages have been described for reactive microglia: (i) activated ramified microglia with elongated soma, long ticker processes, (ii) ameboid microglia with round-shaped soma and short tick processes, (iii) phagocitic microglia with round-shaped soma and vacuolated cytoplasm, void of processes $[49,54]$. Moreover, microglia can 


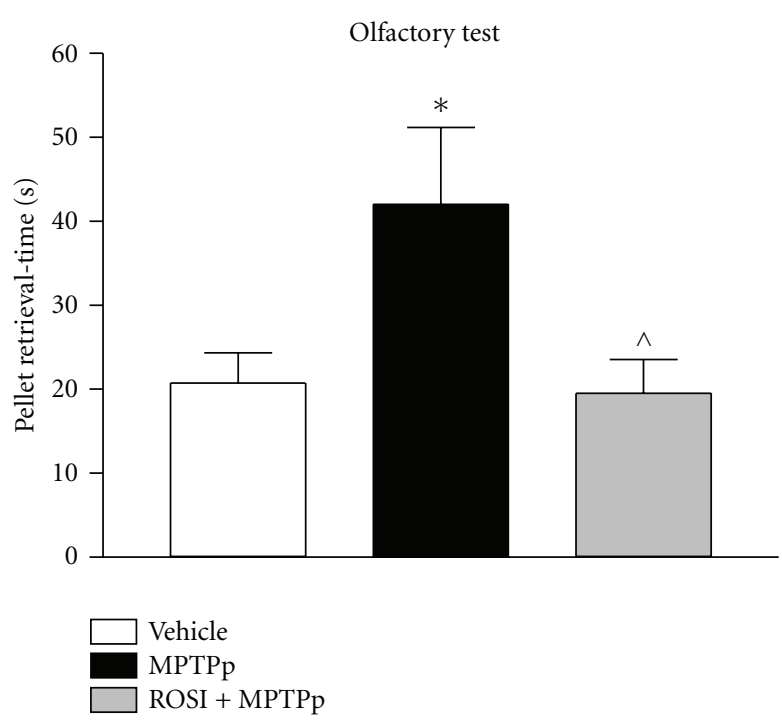

(a)

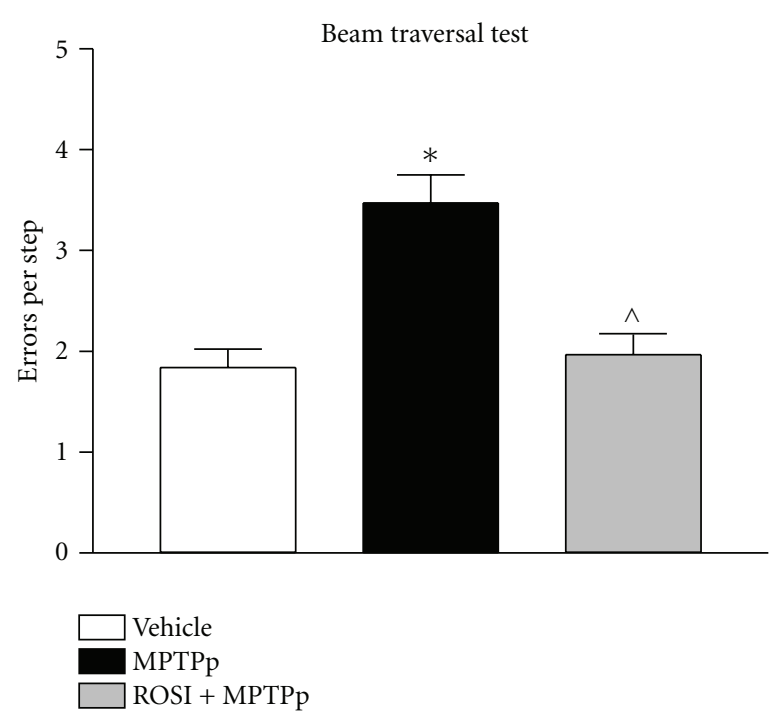

(b)

FIGURE 1: PPAR- $\gamma$ agonist rosiglitazone prevents the development of behavioural deficits, as olfactory dysfunction and motor impairment, in a chronic model of progressive PD [15].

assume different states of effector functions, likely in relation with the activating stimulus and disease state [55]. Depending on the environment and level of threat for the SNC, microglia can temporarily assume a ctotoxic phenotype with phagocytic functions that is associated with production of pro-inflammatory cytokines as TNF- $\alpha$, interleukin (IL) $-1 \beta$, IL-2, IL-6, and nitric oxide (NO). Alternatively, microglia can act as antigen-presenting cells, expressing the major histocompatibility complex $(\mathrm{MCH})$ class II, being therefore able to interact with adaptive immunity cells ( $\mathrm{T}$ cells). In turn, $\mathrm{T}$ cells can stimulate microglia to assume either a cytotoxic phenotype or a phenotype with functions of neuroprotection and cell renewal through the upregulation of beneficial factors as insulin-like growth factor (IGF)1 and anti-inflammatory cytokines and downregulation of neurodegenerative compounds, as TNF- $\alpha[56,57]$.

5.2. Reactive Gliosis in PD: Human. In PD, postmortem studies have reported presence of activated microglia agglomerates around degenerating dopaminergic neurons and extracellular melanin in the SNc [46]. Moreover, proinflammatory cytokines, as TNF- $\alpha$, IL-1 $\beta$, IL-2, and IL-6 have been found in high levels in parkinsonian brains as well as in the serum and cerebrospinal fluid of PD patients [44, 58-62]. Accordingly, increased levels and nuclear translocation of nuclear factor (NF)-kB, a transcription factor controlling cytokines expression, were also observed in the $\mathrm{SNc}$ of PD patients [63, 64]. Interestingly, in PD gliosis seems to be limited to microglial activation. Indeed, most reports did not find reactive astrocytosis in the SN of PD patients, suggesting that the inflammatory process in $\mathrm{PD}$ is a unique phenomenon diverse from other neurodegenerative disorders (Mirza et al. [65]).
5.3. Reactive Gliosis in PD: Experimental PD. Studies in animal models of PD support the involvement of neuroinflammation and pro-inflammatory cytokines in dopaminergic neurodegeneration. MPTP and 6-OHDA-induced neurotoxicity in rodents are associated with an intense microglial reaction and with elevated levels of pro-inflammatory cytokines in the SNc [41, 66-72]. Moreover, in the LPS inflammatory model of neurodegeneration, systemic LPS induces intense neuroinflammation and increased levels of pro-inflammatory cytokines in the mouse brain, followed by dopaminergic degeneration in the SNc [73]. Accordingly, an atypical production of pro-inflammatory cytokines has been described in a 6-OHDA model of PD, where microglial activation was associated with a selective subset of cytokines increase [67]. Remarkably, 6-OHDA-induced dopaminergic neurodegeneration is exacerbated by the overexpression, and decreased by inhibition, of the pro-inflammatory cytokine IL- $1 \beta$, whereas chronic TNF- $\alpha$ expression elicits nigral degeneration, which demonstrate a direct involvement of toxic cytokines in DA neurons degeneration $[54,74]$.

Although most reports of reactive microglia in the PD brain were derived from observations of terminal stage cases, leaving unknown if reactive gliosis is a cause or consequence of the disease, findings from animal models of PD suggest that microglia is chronically activated in a neurotoxic phenotype [44] (Figure 2). Products of degenerating neurons in $\mathrm{PD}$, as aggregated $\alpha$-synuclein, ATP, and neuromelanin, may act as self-antigen to activate microglia in order to induce a defensive reaction $[47,75-78]$. However, in PD, activated microglia is engaged in a vicious cycle of inflammation, where products from dying neurons and inflammatory compounds chronically released by the microglia itself may sustain a condition called reactive microgliosis, in which neuroinflammation propagates and amplifies to destroy 


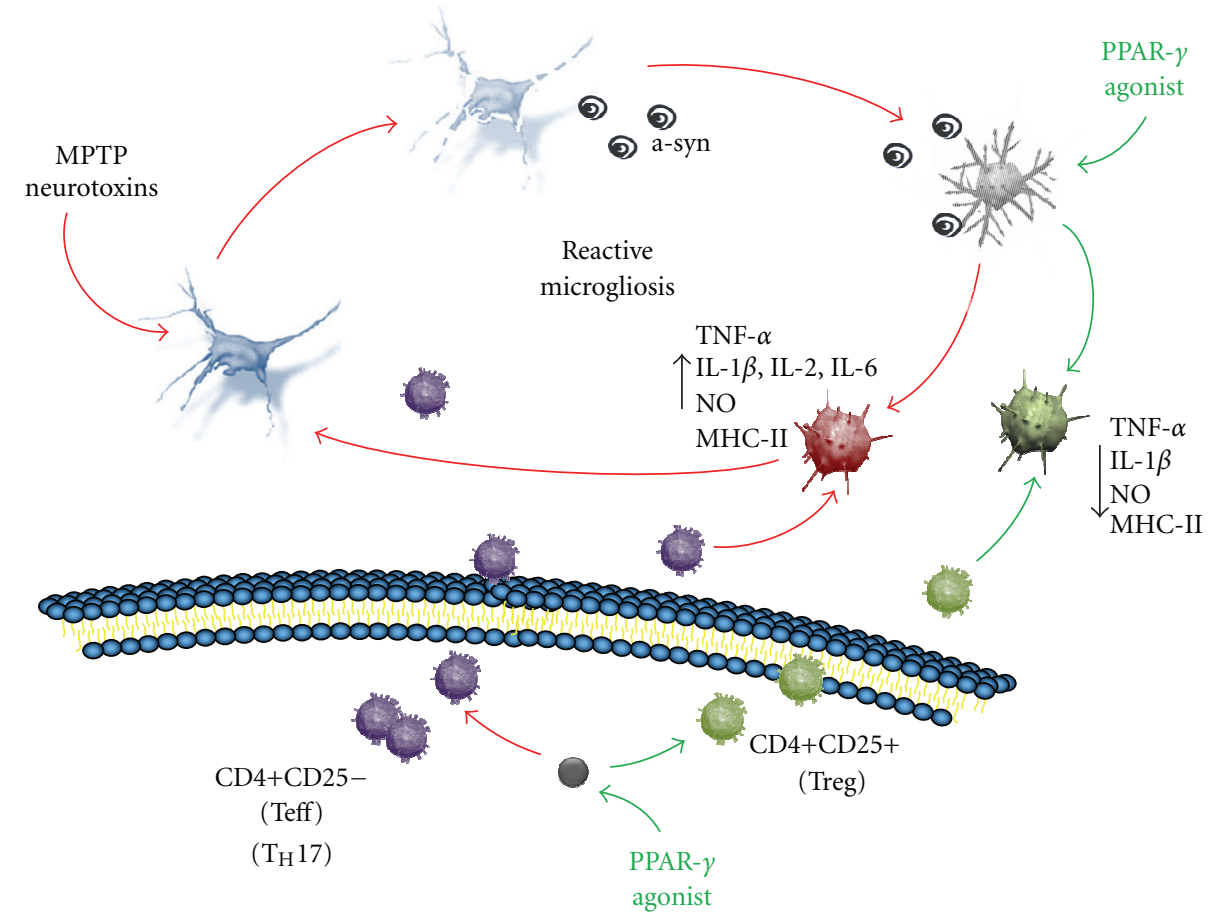

FIGURE 2: PPAR- $\gamma$ agonists might achieve neuroprotection in PD by anti-inflammatory activity targeting cells of the central and peripheral immune systems. Products from dying neurons as $\alpha$-synuclein ( $\alpha$-syn), ATP, and neuromelanin activate microglia to assume a proinflammatory phenotype that will be involved in clearing the environment from dangerous agents through the release of factors such as cytokines endowed with inflammatory and recruitment properties. In PD, microglia might have lost the ability to self-modulate, chronically maintaining a pro-inflammatory phenotype (red microglia) and failing to assume an anti-inflammatory and neuroprotective function (green microglia). Activated microglia becomes, therefore, engaged in a vicious cycle called reactive microgliosis, in which sustained neuroinflammation contributes to neuronal damage. PPAR- $\gamma$, through the specific inhibition of pro-inflammatory cytokines production and a stimulatory effect on anti-inflammatory cytokines, may suppress the microglia activation toward a pro-inflammatory/neurotoxic phenotypes, while directing it toward a neuroprotective phenotype (see text for references). In addition, in PD peripheral T lymphocytes activation is altered in that pro-inflammatory phenotypes (violet) exceed anti-inflammatory ones (green). Abnormally activated T cells infiltrate into the CNS, reaching the damaged SNc. Herein, they may drive microglia to acquire the neurotoxic phenotype to the detriment of less toxic or neuroprotective states, actively contributing to the pathological processes. Peripheral PPAR- $\gamma$ can direct lymphocytes activation, selectively suppressing subsets of activated $\mathrm{T}$ cells which sustain tissue inflammation. Counteracting the disease-dysregulated peripheral immune functions by PPAR- $\gamma$ agonists may, therefore, represent an adjunctive target for neuroprotection (see text for references).

more neurons [44, 67, 79-83] (Figure 2). In such a toxic environment, it has been suggested that the elevated plasticity of microglia and their interaction with adaptive immunity cells (see later in this review) may lead them to assume maladaptive functions, loosing their ability to self-modulate themselves therefore perpetuating a neurotoxic phenotype of activation, while failing to assume a neuroprotective function [53, 76] (Figure 2). This view would prompt for search of therapeutic strategies aimed at finely modulate microglia activation. Optimal anti-inflammatory therapies with neuroprotective target should be directed at selectively suppress dangerous microglia phenotypes while stimulating the neuroprotective ones, rather than generally suppress microglia activation.

5.4. PPAR- $y$ Agonists and Reactive Gliosis in PD. Studies in PD models in vivo have shown that PPAR- $\gamma$ agonistsmediated neuroprotection is consistently associated with inhibition of microglial reactivity (Table 2). In MPTPexposed mice, the neuroprotective effect of pioglitazone was associated with the inhibition of microglial reactivity in the $\mathrm{SNc}[8,9]$. Since pioglitazone exerts an inhibitory effect on monoamine oxidase $\mathrm{B}$ (MAO-B), therefore blocking the conversion of MPTP to the toxic metabolite MPP+, it has been claimed that this mechanism might account, at least partly, for the neuroprotective activity displayed by this drug upon MPTP intoxication [84] (Table 2). However, in a different PD model obtained by intrastriatal infusion of lipopolysaccharide (LPS), neuroprotection by pioglitazone was associated with inhibition of microglial reactivity in the $\mathrm{SNc}$ and inhibition of LPS-induced increase in mitochondrial proteins uncoupling protein 2 (UPS2) and mitoNEET $[42,43]$. Moreover, in a recent study conducted by our group in a mouse model of progressive PD induced by chronic delivery of MPTPp, rosiglitazone prevented microglia activation [15]. Interestingly, while microglial response was fully prevented by rosiglitazone in 


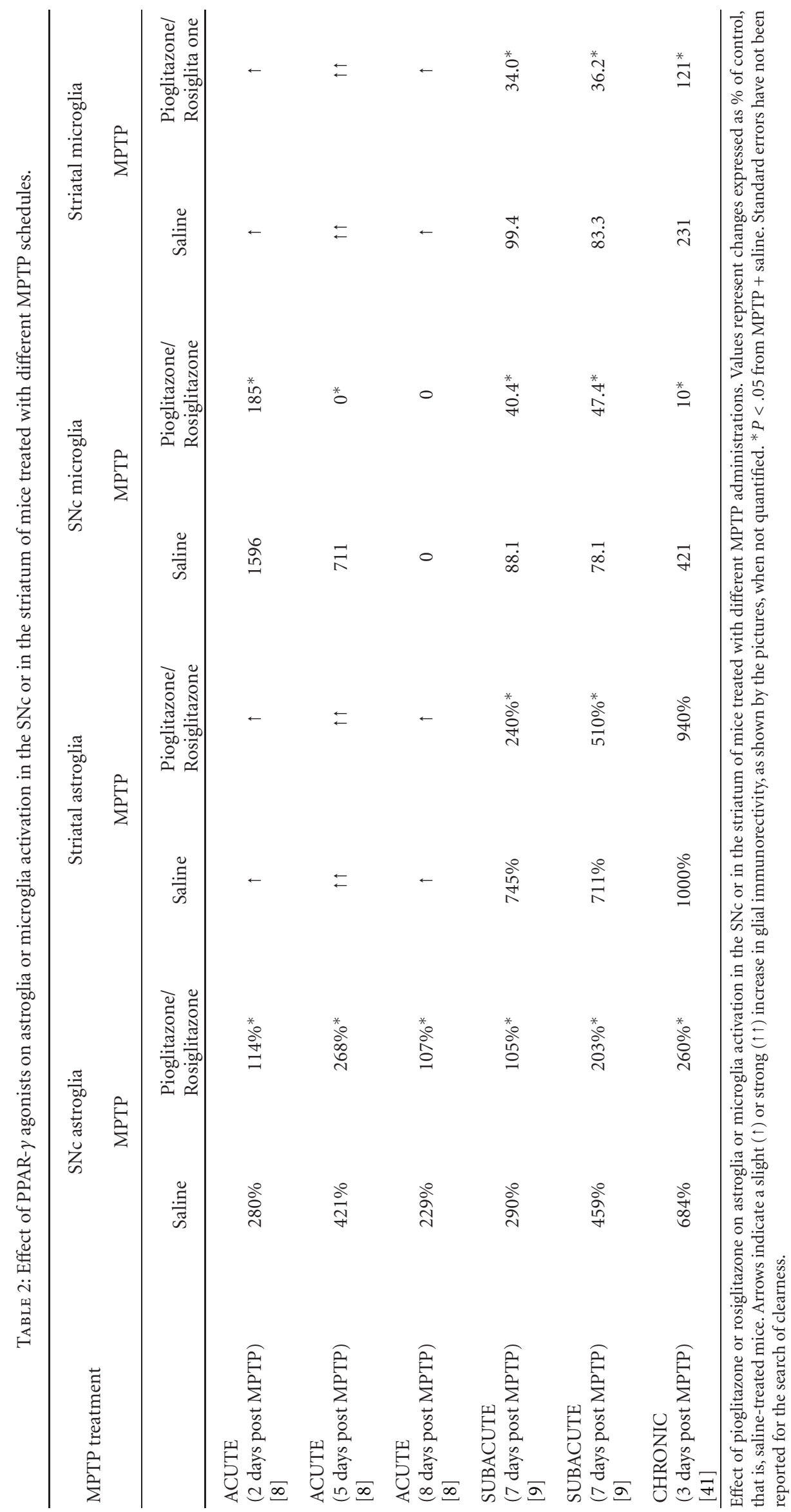


the SNc, in line with a complete preservation of DA cell bodies, in the striatum, a partial microglia inhibition was associated with a partial rescue of DA content decline, further interrelating the anti-inflammatory activity with the neuroprotective effect [15]. Furthermore, when rosiglitazone was introduced late in the chronic MPTP treatment, in presence of an intense microgliosis and partial dopaminergic degeneration, microglial response was partially inhibited (unpublished observation). Importantly, in contrast to pioglitazone, MPP+ levels were not altered by rosiglitazone in mice chronically treated with MPTP, ruling out an effect on MPTP metabolism [15].

Several NSAID, as ibuprofen, fenoprofen, flufenamidic acid, indometacin, display a PPAR- $\gamma$ agonistic activity $[3,4]$. Noteworthy, these drugs have provided neuroprotection in PD models, supporting a role for the anti-inflammatory activity as mechanism of PPAR- $\gamma$-mediated neuroprotection [85].

5.5. Modulation of Microglial Response as a Mechanism of PPAR- $\gamma$-Mediated Neuroprotection. Although the preclinical studies suggest the anti-inflammatory activity as a mechanism of neuroprotection by PPAR- $\gamma$ agonists in PD, a direct causal link has not been demonstrated. The in vivo studies in PD models have reported the inhibition of iNOS synthesis by pioglitazone, through an inhibition of NF$\mathrm{kB}$ activation, a main regulator of inflammatory genes transcription, both in neurons and glial cells, offering a molecular mechanism for an anti-inflammatory-mediated neuroprotection [9]. Accordingly, in an in vitro study conducted in mesencephalic neuron-microglia mixed cultures, pioglitazone inhibited LPS-induced cyclooxygenase-2 (COX2) activity, iNOS expression, NO production and p38 MAPK activity, achieving neuroprotection [86, 87].

Moreover, a direct evidence for PPAR- $\gamma$-mediated modulation of cytokines expression in experimental PD models in vivo is lacking although a wealth of evidences supporting this effect as a mechanism of neuroprotection come from in vitro studies. In LPS-stimulated microglial cells, natural and synthetic PPAR- $\gamma$ agonists were shown to inhibit the production of pro-inflammatory and neurotoxic mediators as TNF- $\alpha$, IL- $1 \beta$, IL-12, iNOS, as well as IFN- $\gamma$-induced expression of major histocompatibility complex (MHC) class II antigen [38, 88-91]. Interestingly, a recent study suggested a role for the anti-inflammatory cytokine IL4 in the PPAR- $\gamma$-mediated inhibitory effect, showing that rosiglitazone attenuated LPS-induced increase of IL- $1 \beta$ and MHC-II in microglia prepared from wild-type mice, but it failed to exert any effect in glia prepared from IL-4-deficient mice [92].

In addition to evidences gained from experimental PD, a number of in vivo and in vitro studies in models of neurodegenerative and neuroinflammatory conditions other than $\mathrm{PD}$, have demonstrated a cytokine-modulatory activity of PPAR- $\gamma$ agonists as mechanism of neuroprotection. In experimental cerebral ischemia, different TZDs, as pioglitazone, troglitazone, and rosiglitazone were neuroprotective and reduced protein and mRNA levels for the pro-inflammatory cytokines IL- $1 \beta$, IL-6, COX-2, and iNOS through an inhibition of NF-kB signaling [93-95]. In an in vitro model of Alzheimer disease, PPAR- $\gamma$ agonists troglitazone and ciglitazone suppressed the expression of the IL- 6 and TNF- $\alpha$ genes in $\mathrm{A} \beta$-stimulated microglial cells, improving neuronal survival [96]. Interestingly, in this study neuroprotection was not achieved by direct application of PPAR- $\gamma$ agonists to the neurons, indicating that PPAR- $\gamma$ agonists were directly targeting microglial function [96].

All together, evidence in PD models and the knowledge gained from diverse neurodegenerative conditions, suggest that PPAR- $\gamma$ agonists may achieve neuroprotection in PD by mean of their anti-inflammatory activity and, specifically, by finely modulating cytokines expression in microglia through a main inhibitory effect on NF-kB activity. The specific inhibition of pro-inflammatory cytokines production by microglia, together with a stimulatory effect on anti-inflammatory cytokines, suggest that PPAR- $\gamma$ agonists may direct activated microglia toward a less toxic or neuroprotective phenotype, while suppressing pro-inflammatory/neurotoxic phenotypes (Figure 2).

BOX. The exact molecular mechanism of the PPAR- $\gamma$ mediated anti-inflammatory activity remains controversial. Upon activation by natural and synthetic agonists, PPAR$\gamma$ heterodimerize with the retinoid $\mathrm{X}$ receptor (RXR) in the cytoplasm, in this form translocating to the nucleus. Herein, it binds to the PPAR- $\gamma$ responsive elements (PPRE) in the promoter region of PPAR target genes to modulate their expression [97-99]. In the absence of ligands, the PPAR/RXR heterodimer is stabilized by the binding of corepressors to suppress transcription, whereas ligandbinding causes release of corepressors and recruitment of co-activators, to activate transcription [100]. Besides this transactivating activity, a ligand-dependent transcriptional transrepression mechanism has been described, by which activated PPAR- $\gamma$ represses gene transcription in a DNAbinding independent way through physically sequestering activated transcriptional factors or their coactivators [101]. For instance, it was recently demonstrated that PPAR- $\gamma$ can inhibit NF-kB by physical interaction with subunit $\mathrm{p} 65$, or by increasing inhibitory kappa B alpha ( $\mathrm{IkB} \alpha$ ) expression [102]. In addition, a small, ubiquitin-like modifier (SUMO)ylation of PPAR- $\gamma$ has been described as a mechanism of transrepression of NF-kB target pro-inflammatory genes, conferring to PPAR- $\gamma$ a ductile function of activator or repressor of NF-kB target genes [103].

\section{PPAR $-\gamma$ and Peripheral Inflammation in PD}

6.1. Peripheral Inflammation in PD: Human. Postmortem as well as in vivo studies in PD patients have suggested that the pathological process leading to neurodegeneration may involve cells of the peripheral immune system and immune-mediated mechanisms. First report by McGeer and colleagues demonstrated the presence of activated $\mathrm{T}$ lymphocytes (CD8+) in the Parkinsonian SN, together with elements of the complement pathway [104, 105]. Thereafter, 
in an elegant study Orr and co-workers demonstrated presence of IgG-immunopositive pigmented neurons in the SN of both idiopathic and genetic forms of PD, associated with an increase of activated microglia expressing high affinity activating $\operatorname{IgG}$ receptors (Fc $\gamma \mathrm{RI})$ [106]. Microglia contained pigment granules, supporting their involvement in a phagocytic attack on IgG immunopositive pigmented neurons [106]. These authors suggested that IgG binding to DA neurons may result in their selective targeting and subsequent destruction by activated microglia [106]. Lately, Brochard and colleagues reported higher densities of CD8+ and $\mathrm{CD} 4+\mathrm{T}$ lymphocytes in the brain of patients with $\mathrm{PD}$ than in healthy brains [107].

Interestingly, abnormalities in peripheral immune functions have been repeatedly described in the blood of patients with $\mathrm{PD}$, which suggest un imbalance toward pro-inflammatory phenotypes for activated $\mathrm{T}$ lymphocytes. Hisanaga and co-workers reported a significantly greater population of circulating CD3+CD4+CD8+ T lymphocytes in blood of PD patients than in age-matched control subjects [108]. In a study conducted in Parkinsonian versus normal individuals, Baba and colleagues suggested a shift of activated lymphocytes to a pro-inflammatory phenotype by showing that patients with PD had significantly decreased CD4+: CD8+ T-cell ratio, fewer CD4+CD25+ T regulatory cells (Treg), and increased ratios of IFN- $\gamma$-producing to IL-4-producing T cells [109]. Accordingly, other studies have reported higher levels of serum interleukins and proinflammatory cytokines $[59,110,111]$.

6.2. Peripheral Inflammation in PD: Experimental PD. Studies in experimental PD models support an involvement of peripheral immunity in dopaminergic cell loss. He et al. [112] demonstrated that injection of IgG from serum of PD patients into the mouse SNc leads to microglial activation and subsequent dopaminergic degeneration, suggesting that humoral immune mechanisms can trigger microglialmediated neuronal injury. Investigating a possible pathological relevance of lymphocytes infiltration in a experimental MPTP model of PD, Brochard et al. [107] showed that MPTP-damaged SNc specifically displayed presence of infiltrating T cells. Moreover, removal of CD4+ T cells in mutant mice resulted in a lower sensitivity to MPTP and lower degree of cell death in the SNc, strongly supporting a deleterious contribution of peripheral lymphocytes to dopaminergic degeneration within the SNc.

Moreover, a role for a dysregulated activation of $\mathrm{T}$ lymphocytes in PD neuropathology has been recently suggested in an in vivo PD model [113]. Thus, inoculation of CD4+CD25+ Treg cells, but not CD4+CD25- effector T cells (Teff), reduced microglial reactivity and neurodegeneration in MPTP-treated mice [113]. In addition, a more recent study by the same authors strongly corroborates the relevance of adaptive immunity cells subpopulations in directing microglial response in PD [114]. Hence, the phenotype undertaken by $\alpha$-synuclein-activated microglia in culture, depended upon the interaction with specific subpopulations of activated T cells, with CD4+CD25+ Treg cells suppressing $\alpha$-synuclein-induced production of reactive oxygen species and NF-kB activation. In contrast, CD4+CD25- effector T cells exacerbated microglial inflammation and neurotoxic responses [76, 114].

Although it is not clear if abnormalities of the peripheral immune system are secondary to changes in central immune system, data from PD cases and experimental PD consistently report an infiltration of abnormally activated immune cells across the blood brain barrier in PD. Consistent with a $\mathrm{T}$ cell function in directing microglia phenotype $[56,57]$, abnormally activated $\mathrm{T}$ cells present in the damaged area may influence the microenvironment by driving microglia to acquire a neurotoxic phenotype to the detriment of less toxic or neuroprotective states, actively contributing to the pathological processes (Figure 2).

\subsection{PPAR-Gamma Agonists and Peripheral Inflammation in} $P D$. PPAR- $\gamma$ agonists exert profound and long-lasting antiinflammatory effects in peripheral immune cells, mainly directing their differentiation into alternate phenotypes [3, $10,115]$. In the light of the growing relevance that peripheral immunity is gaining in PD pathology, this unique feature of PPAR- $\gamma$ agonists sues for further attention toward these drugs as disease modifying strategy in PD. Albeit a direct evidence for a contribution of this mechanism in PPAR$\gamma$-mediated neuroprotection in PD is currently missing, a wealth of data indicate that modulation of peripheral immunity is a main target for PPAR- $\gamma$-mediated protective therapies in chronic inflammatory diseases, including neuroinflammatory conditions as multiple sclerosis, where a dysregulation of the peripheral immune system is instrumental to the pathology.

PPAR- $\gamma$ can affect adaptive immune responses by modulating $\mathrm{T}$ cells differentiation and activity through mechanisms involving the suppression of pro-inflammatory cytokines, as IL-2, which are known to play an important role in directing $\mathrm{T}$ cells phenotype [116-118]. Noteworthy, PPAR- $\gamma$-mediated suppression of a particular subset of activated $\mathrm{T}$ cells, named $\mathrm{T}$ helper $17\left(\mathrm{~T}_{\mathrm{H}} 17\right)$, provides beneficial effects to multiple sclerosis patients, asserting PPAR- $\gamma$ as a promising target for specific immunointervention in autoimmune disorders [119]. $\mathrm{T}_{\mathrm{H}} 17$ has been recently described, playing an important role in inducing autoimmune tissue inflammations by the preferential release of IL-17. IL-17 in turn promotes inflammation through the production of pro-inflammatory cytokines as IL- 6 , TNF- $\alpha$, IL- $1 \beta$, chemokines, and potentiate tissue pathology by inducing the production of nitric oxide and matrix metalloproteinases [120]. Evidencing the prominent role played by PPAR- $\gamma$ in the development of autoimmunity, rosiglitazone can affect $\mathrm{CD} 4+\mathrm{T}$ cells function by specifically suppressing their differentiation into $\mathrm{T}_{\mathrm{H}} 17$ $[117,119]$.

In addition to the anti-inflammatory function in adaptive immune cells, PPAR- $\gamma$ agonists suppress monocyte elaboration of inflammatory cytokines and can prime monocytes to differentiate into macrophages with an anti-inflammatory phenotype $[3,121,122]$. In human 
atherosclerotic lesions, and in cultured human monocytes, PPAR- $\gamma$ stimulation primed primary human monocytes to be differentiated into the M2 form, the "alternative" antiinflammatory macrophage phenotype. This in turn affected M1 macrophages, which displayed a more pronounced anti-inflammatory activity (the "classical" proatherogenic phenotype) [122-124].

To summarize, peripheral PPAR- $\gamma$ holds the double function of selectively suppressing CD4+ activated T cells that sustain tissue inflammation and of inducing macrophages to differentiate into the anti-inflammatory M2 phenotype. Therefore, this receptor contributes to keep in control the inflammatory reactions in the tissue microenvironment and to maintain immune homeostasis, either in the presence of foreign pathogens/antigens or self-peptides insults. Within a view that includes a role for humoral immunity in $\mathrm{PD}$ pathogenesis, the restoration of disease-dysregulated peripheral immune functions by PPAR- $\gamma$ agonists, may represent an adjunctive target for neuroprotection in this neurodegenerative disorder, prompting for further investigation in this field (Figure 2).

\section{Conclusions and Future Perspectives}

Currently, available drugs for PD therapy only provide symptomatic amelioration, while therapeutic strategies aimed at stopping or modifying disease progression are still strongly sought. Neuroinflammation plays a crucial role in the neurodegenerative processes. Most recent research suggests that both the central and peripheral immune systems are dysregulated in $\mathrm{PD}$, as suggested by a chronic prevalence of a neurotoxic phenotype over anti-inflammatory states of activation, reported for either microglia or T cells. Therefore, therapeutic strategies aimed at finely modulating microglial activation, reinstating the physiological shift toward less neurotoxic phenotypes, may represent a goal in neuroprotection. This goal may be achieved by using PPAR- $\gamma$ agonists, because their ability in modulating the expression of pro- and antiinflammatory cytokines at the transcriptional level in both central and peripheral immune cells.

While the ability of PPAR- $\gamma$ agonists to prevent neurodegeneration has been demonstrated in several experimental models of PD, additional studies are needed to prove PPAR$\gamma$ agonists efficacy on disease progression. Moreover, in spite of recent warning on the safety of these drugs in diabetes, to our knowledge no safety records are available in non diabetic individuals or PD patients. Therefore, translation to the clinical trial is warranted to fully evaluate the therapeutic potential in PD although safety could become a critical issue.

\section{References}

[1] A. H. Barnett, "Redefining the role of thiazolidinediones in the management of type 2 diabetes," Vascular Health and Risk Management, vol. 5, pp. 141-151, 2009.

[2] A. Bernardo and L. Minghetti, "Regulation of glial cell functions by PPAR- $\gamma$ natural and synthetic agonists," PPAR Research, vol. 2008, Article ID 864140, 2008.
[3] C. Jiang, A. T. Ting, and B. Seed, "PPAR- $\gamma$ agonists inhibit production of monocyte inflammatory cytokines," Nature, vol. 391, no. 6662, pp. 82-86, 1998.

[4] J. M. Lehmann, J. M. Lenhard, B. B. Oliver, G. M. Ringold, and S. A. Kliewer, "Peroxisome proliferator-activated receptors $\alpha$ and $\gamma$ are activated by indomethacin and other non-steroidal anti-inflammatory drugs," Journal of Biological Chemistry, vol. 272, no. 6, pp. 3406-3410, 1997.

[5] M. Ricote, A. C. Li, T. M. Willson, C. J. Kelly, and C. K. Glass, "The peroxisome proliferator-activated receptor- $\gamma$ is a negative regulator of macrophage activation," Nature, vol. 391, no. 6662, pp. 79-82, 1998.

[6] D. S. Straus and C. K. Glass, "Anti-inflammatory actions of PPAR ligands: new insights on cellular and molecular mechanisms," Trends in Immunology, vol. 28, no. 12, pp. 551558, 2007.

[7] E. L. Akuffo, J. B. Davis, S. M. Fox et al., "The discovery and early validation of novel plasma biomarkers in mildto-moderate Alzheimer's disease patients responding to treatment with rosiglitazone," Biomarkers, vol. 13, no. 6, pp. 618-636, 2008.

[8] T. Breidert, J. Callebert, M. T. Heneka, G. Landreth, J. M. Launay, and E. C. Hirsch, "Protective action of the peroxisome proliferator-activated receptor- $\gamma$ agonist pioglitazone in a mouse model of Parkinson's disease," Journal of Neurochemistry, vol. 82, no. 3, pp. 615-624, 2002.

[9] T. Dehmer, M. T. Heneka, M. Sastre, J. Dichgans, and J. B. Schulz, "Protection by pioglitazone in the MPTP model of Parkinson's disease correlates with $\mathrm{I} \kappa \mathrm{B} \alpha$ induction and block of NFkB and iNOS activation," Journal of Neurochemistry, vol. 88, no. 2, pp. 494-501, 2004.

[10] M. T. Heneka, G. E. Landreth, and M. Hüll, "Drug insight: effects mediated by peroxisome proliferator-activated receptor- $\gamma$ in CNS disorders," Nature Clinical Practice Neurology, vol. 3, no. 9, pp. 496-504, 2007.

[11] M. C. Irizarry, D. J. Webb, C. Bains et al., "Predictors of placebo group decline in the Alzheimer's disease assessment scale-cognitive subscale (ADAS-Cog) in 24 week clinical trials of Alzheimer's disease," Journal of Alzheimer's Disease, vol. 14, no. 3, pp. 301-311, 2008.

[12] M. Kiaei, K. Kipiani, J. Chen, N. Y. Calingasan, and M. F. Beal, "Peroxisome proliferator-activated receptor-gamma agonist extends survival in transgenic mouse model of amyotrophic lateral sclerosis," Experimental Neurology, vol. 191, no. 2, pp. 331-336, 2005.

[13] Y. Luo, W. Yin, A. P. Signore et al., "Neuroprotection against focal ischemic brain injury by the peroxisome proliferatoractivated receptor- $\gamma$ agonist rosiglitazone," Journal of Neurochemistry, vol. 97, no. 2, pp. 435-448, 2006.

[14] S.-W. Park, J.-H. Yi, G. Miranpuri et al., "Thiazolidinedione class of peroxisome proliferator-activated receptor $\gamma$ agonists prevents neuronal damage, motor dysfunction, myelin loss, neuropathic pain, and inflammation after spinal cord injury in adult rats," Journal of Pharmacology and Experimental Therapeutics, vol. 320, no. 3, pp. 1002-1012, 2007.

[15] N. Schintu, L. Frau, M. Ibba et al., "PPAR-gamma-mediated neuroprotection in a chronic mouse model of Parkinson's disease," European Journal of Neuroscience, vol. 29, no. 5, pp. 954-963, 2009.

[16] S. E. Nissen and K. Wolski, "Effect of rosiglitazone on the risk of myocardial infarction and death from cardiovascular causes," The New England Journal of Medicine, vol. 356, no. 24, pp. 2457-2471, 2007. 
[17] H. J. Dargie, P. R. Hildebrandt, G. A. J. Riegger et al., "A randomized, placebo-controlled trial assessing the eff ects of rosiglitazone on echocardiographic function and cardiac status in type 2 diabetic patients with New York heart association functional class I or II heart failure," Journal of the American College of Cardiology, vol. 49, no. 16, pp. 16961704, 2007.

[18] P. D. Home, S. J. Pocock, H. Beck-Nielsen et al., "Rosiglitazone evaluated for cardiovascular outcomes in oral agent combination therapy for type 2 diabetes (RECORD): a multicentre, randomised, open-label trial," The Lancet, vol. 373, no. 9681, pp. 2125-2135, 2009.

[19] S. E. Kahn, S. M. Haffner, M. A. Heise et al., "Glycemic durability of rosiglitazone, metformin, or glyburide monotherapy," The New England Journal of Medicine, vol. 355, no. 23, pp. 2427-2443, 2006.

[20] R. W. Nesto, D. Bell, R. O. Bonow et al., "Thiazolidinedione use, fl uid retention, and congestive heart failure: a consensus statement from the American Heart Association and American Diabetes Association," Circulation, vol. 108, no. 23, pp. 2941-2948, 2003.

[21] The DREAM (Diabetes REduction Assessment with ramipril and rosiglitazone Medication) Trial Investigators, H. C. Gerstein, S. Yusuf et al., "Effect of rosiglitazone on the frequency of diabetes in patients with impaired glucose tolerance or impaired fasting glucose: a randomised controlled trial," The Lancet, vol. 368, no. 9541, pp. 1096-1105, 2006.

[22] J. A. Dormandy, B. Charbonnel, D. J. Eckland et al., "Secondary prevention of macrovascular events in patients with type 2 diabetes in the PROactive Study (PROspective pioglitAzone Clinical Trial in macroVascular Events): a randomised controlled trial," The Lancet, vol. 366, no. 9493, pp. 1279-1289, 2005.

[23] S. E. Nissen and K. Wolski, "Rosiglitazone revisited: an updated meta-analysis of risk for myocardial infarction and cardiovascular mortality," Archives of Internal Medicine, vol. 170, no. 14, pp. 1191-1201, 2010.

[24] R. A. Ajjan and P. J. Grant, "The cardiovascular safety of rosiglitazone," Expert Opinion on Drug Safety, vol. 7, no. 4, pp. 367-376, 2008.

[25] M. I. Freed, R. Ratner, S. M. Marcovina et al., "Effects of rosiglitazone alone and in combination with atorvastatin on the metabolic abnormalities in type 2 diabetes mellitus," American Journal of Cardiology, vol. 90, no. 9, pp. 947-952, 2002.

[26] O. Barbier, I. P. Torra, Y. Duguay et al., "Pleiotropic actions of peroxisome proliferator-activated receptors in lipid metabolism and atherosclerosis," Arteriosclerosis, Thrombosis, and Vascular Biology, vol. 22, no. 5, pp. 717-726, 2002.

[27] M. Komajda, P. Curtis, M. Hanefeld et al., "Effect of the addition of rosiglitazone to metformin or sulfonylureas versus metformin/sulfonylurea combination therapy on ambulatory blood pressure in people with type 2 diabetes: a randomized controlled trial (the RECORD study)," Cardiovascular Diabetology, vol. 7, article 10, 2008.

[28] A. Amoruso, C. Bardelli, G. Gunella, L. G. Fresu, V. Ferrero, and S. Brunelleschi, "Quantification of PPAR- $\gamma$ protein in monocyte/macrophages from healthy smokers and nonsmokers: a possible direct effect of nicotine," Life Sciences, vol. 81, no. 11, pp. 906-915, 2007.

[29] O. Braissant, F. Foufelle, C. Scotto, M. Dauça, and W. Wahli, "Differential expression of peroxisome proliferator-activated receptors (PPARs): tissue distribution of PPAR $-\alpha,-\beta$, and $-\gamma$ in the adult rat," Endocrinology, vol. 137, no. 1, pp. 354-366, 1996.

[30] A. C. Li and W. Palinski, "Peroxisome proliferator-activated receptors: how their effects on macrophages can lead to the development of a new drug therapy against atherosclerosis," Annual Review of Pharmacology and Toxicology, vol. 46, pp. 1-39, 2006.

[31] E. Rigamonti, C. Fontaine, B. Lefebvre et al., "Induction of CXCR2 receptor by peroxisome proliferator-activated receptor $\gamma$ in human macrophages," Arteriosclerosis, Thrombosis, and Vascular Biology, vol. 28, no. 5, pp. 932-939, 2008.

[32] A. Szanto and T. Roszer, "Nuclear receptors in macrophages: a link between metabolism and inflammation," FEBS Letters, vol. 582, no. 1, pp. 106-116, 2008.

[33] B. Desvergne, L. Michalik, and W. Wahli, "Be fit or be sick: peroxisome proliferator-activated receptors are down the road," Molecular Endocrinology, vol. 18, no. 6, pp. 13211332, 2004.

[34] E. D. Rosen, P. Sarraf, A. E. Troy et al., "PPAR $\gamma$ is required for the differentiation of adipose tissue in vivo and in vitro," Molecular Cell, vol. 4, no. 4, pp. 611-617, 1999.

[35] R. Cunard, M. Ricote, D. DiCampli et al., "Regulation of cytokine expression by ligands of peroxisome proliferator activated receptors," Journal of Immunology, vol. 168, no. 6, pp. 2795-2802, 2002.

[36] T. E. Cullingford, K. Bhakoo, S. Peuchen, C. T. Dolphin, R. Patel, and J. B. Clark, "Distribution of mRNAs encoding the peroxisome proliferator-activated receptor $\alpha, \beta$, and $\gamma$ and the retinoid $\mathrm{X}$ receptor $\alpha, \beta$, and $\gamma$ in rat central nervous system," Journal of Neurochemistry, vol. 70, no. 4, pp. 1366$1375,1998$.

[37] S. Moreno, S. Farioli-vecchioli, and M. P. Cerù, "Immunolocalization of peroxisome proliferator-activated receptors and retinoid X receptors in the adult rat CNS," Neuroscience, vol. 123, no. 1, pp. 131-145, 2004.

[38] A. Bernardo, G. Levi, and L. Minghetti, "Role of the peroxisome proliferator-activated receptor- $\gamma$ (PPAR- $\gamma$ ) and its natural ligand 15-deoxy- $\Delta(12,14)$-prostaglandin $\mathrm{J}$ in the regulation of microglial functions," European Journal of Neuroscience, vol. 12, no. 7, pp. 2215-2223, 2000.

[39] A. Cimini, E. Benedetti, L. Cristiano et al., "Expression of peroxisome proliferator-activated receptors (PPARs) and retinoic acid receptors (RXRs) in rat cortical neurons," Neuroscience, vol. 130, no. 2, pp. 325-337, 2005.

[40] C. W. Olanow, "The pathogenesis of cell death in Parkinson's disease-2007," Movement Disorders, vol. 22, supplement 17, pp. S335-S342, 2007.

[41] N. Schintu, L. Frau, M. Ibba, A. Garau, E. Carboni, and A. R. Carta, "Progressive dopaminergic degeneration in the chronic MPTPp mouse model of parkinson's disease," Neurotoxicity Research, vol. 16, no. 2, pp. 127-139, 2009.

[42] R. L. Hunter, N. Dragicevic, K. Seifert et al., "Inflammation induces mitochondrial dysfunction and dopaminergic neurodegeneration in the nigrostriatal system," Journal of Neurochemistry, vol. 100, no. 5, pp. 1375-1386, 2007.

[43] R. L. Hunter, D. Y. Choi, S. A. Ross, and G. Bing, "Protective properties afforded by pioglitazone against intrastriatal LPS in Sprague-Dawley rats," Neuroscience Letters, vol. 432, no. 3, pp. 198-201, 2008.

[44] E. C. Hirsch and S. Hunot, "Neuroinflammation in Parkinson's disease: a target for neuroprotection?" The Lancet Neurology, vol. 8, no. 4, pp. 382-397, 2009.

[45] C. M. Long-Smith, A. M. Sullivan, and Y. M. Nolan, "The influence of microglia on the pathogenesis of Parkinson's 
disease," Progress in Neurobiology, vol. 89, no. 3, pp. 277-287, 2009.

[46] P. L. McGeer and E. G. McGeer, "Glial reactions in Parkinson's disease," Movement Disorders, vol. 23, no. 4, pp. 474483, 2008.

[47] D. Davalos, J. Grutzendler, G. Yang et al., "ATP mediates rapid microglial response to local brain injury in vivo," Nature Neuroscience, vol. 8, no. 6, pp. 752-758, 2005.

[48] M. B. Graeber, "Changing face of microglia," Science, vol. 330, no. 6005 , pp. 783-788, 2010.

[49] G. W. Kreutzberg, "Microglia: a sensor for pathological events in the CNS," Trends in Neurosciences, vol. 19, no. 8, pp. 312-318, 1996.

[50] A. Nimmerjahn, F. Kirchhoff, and F. Helmchen, "Neuroscience: resting microglial cells are highly dynamic surveillants of brain parenchyma in vivo," Science, vol. 308, no. 5726, pp. 1314-1318, 2005.

[51] G. Raivich, "Like cops on the beat: the active role of resting microglia," Trends in Neurosciences, vol. 28, no. 11, pp. 571573, 2005.

[52] F. Ginhoux, M. Greter, and M. Leboeuf et al., "Fate mapping analysis reveals that adult microglia derive from primitive macrophages," Science, vol. 330, no. 6005, pp. 841-845, 2010.

[53] M. Schwartz, O. Butovsky, W. Brück, and U. K. Hanisch, "Microglial phenotype: is the commitment reversible?" Trends in Neurosciences, vol. 29, no. 2, pp. 68-74, 2006.

[54] M. C. P. Godoy, R. Tarelli, C. C. Ferrari, M. I. Sarchi, and F. J. Pitossi, "Central and systemic IL-1 exacerbates neurodegeneration and motor symptoms in a model of Parkinson's disease," Brain, vol. 131, no. 7, pp. 1880-1894, 2008.

[55] R. M. Ransohoff and V. H. Perry, "Microglial physiology: unique stimuli, specialized responses," Annual Review of Immunology, vol. 27, pp. 119-145, 2009.

[56] O. Butovsky, A. E. Talpalar, K. Ben-Yaakov, and M. Schwartz, "Activation of microglia by aggregated $\beta$-amyloid or lipopolysaccharide impairs MHC-II expression and renders them cytotoxic whereas IFN- $\gamma$ and IL-4 render them protective," Molecular and Cellular Neuroscience, vol. 29, no. 3, pp. 381-393, 2005.

[57] I. Shaked, D. Tchoresh, R. Gersner et al., "Protective autoimmunity: interferon- $\gamma$ enables microglia to remove glutamate without evoking inflammatory mediators," Journal of Neurochemistry, vol. 92, no. 5, pp. 997-1009, 2005.

[58] D. Blum-Degena, T. Müller, W. Kuhn, M. Gerlach, H. Przuntek, and P. Riederer, "Interleukin- $1 \beta$ and interleukin-6 are elevated in the cerebrospinal fluid of Alzheimer's and de novo Parkinson's disease patients," Neuroscience Letters, vol. 202, no. 1-2, pp. 17-20, 1995.

[59] R. J. Dobbs, A. Charlett, A. G. Purkiss, S. M. Dobbs, C. Weller, and D. W. Peterson, "Association of circulating TNF$\alpha$ and IL-6 with ageing and parkinsonism," Acta Neurologica Scandinavica, vol. 100, no. 1, pp. 34-41, 1999.

[60] S. Hunot, N. Dugas, B. Faucheux et al., "FceRII/CD23 is expressed in Parkinson's disease and induces, in vitro, production of nitric oxide and tumor necrosis factor- $\alpha$ in glial cells," Journal of Neuroscience, vol. 19, no. 9, pp. 34403447, 1999.

[61] M. Mogi, M. Harada, T. Kondob et al., "Interleukin-1 $\beta$, interleukin-6, epidermal growth factor and transforming growth factor- $\alpha$ are elevated in the brain from parkinsonian patients," Neuroscience Letters, vol. 180, no. 2, pp. 147-150, 1994.
[62] M. Mogi, M. Harada, P. Riederer, H. Narabayashi, K. Fujita, and T. Nagatsu, "Tumor necrosis factor- $\alpha$ (TNF- $\alpha$ ) increases both in the brain and in the cerebrospinal fluid from parkinsonian patients," Neuroscience Letters, vol. 165, no. 1-2, pp. 208-210, 1994.

[63] S. Hunot, B. Brugg, D. Ricard et al., "Nuclear translocation of NF- $\kappa b$ is increased in dopaminergic neurons of patients with Parkinson disease," Proceedings of the National Academy of Sciences of the United States of America, vol. 94, no. 14, pp. 7531-7536, 1997.

[64] M. Mogi, T. Kondo, Y. Mizuno, and T. Nagatsu, "p53 protein, interferon $-\gamma$, and NF- $\kappa$ B levels are elevated in the parkinsonian brain," Neuroscience Letters, vol. 414, no. 1, pp. 94-97, 2007.

[65] B. Mirza, H. Hadberg, P. Thomsen, and T. Moos, "The absence of reactive astrocytosis is indicative of a unique inflammatory process in Parkinson's disease," Neuroscience, vol. 95, no. 2, pp. 425-432, 2000.

[66] F. Blandini, M. T. Armentero, and E. Martignoni, "The 6hydroxydopamine model: news from the past," Parkinsonism and Related Disorders, vol. 14, supplement 2, pp. S124-S129, 2008.

[67] A. M. Depino, C. Earl, E. Kaczmarczyk et al., "Microglial activation with atypical proinflammatory cytokine expression in a rat model of Parkinson's disease," European Journal of Neuroscience, vol. 18, no. 10, pp. 2731-2742, 2003.

[68] I. 59. Kurkowska-Jastrzebska, A. Wrońska, M. Kohutnicka, A. Członkowski, and A. Członkowska, "MHC class II positive microglia and lymphocytic infiltration are present in the substantia nigra and striatum in mouse model of Parkinson's disease," Acta Neurobiologiae Experimentalis, vol. 59, no. 1, pp. 1-8, 1999.

[69] D. D. Lofrumento, C. Saponaro, A. Cianciulli et al., "MPTPinduced neuroinflammation increases the expression of proinflammatory cytokines and their receptors in mouse brain," NeuroImmunoModulation, vol. 18, no. 2, pp. 79-88, 2010.

[70] D. W. Luchtman, DI. Shao, and C. Song, "Behavior, neurotransmitters and inflammation in three regimens of the MPTP mouse model of Parkinson's disease," Physiology and Behavior, vol. 98, no. 1-2, pp. 130-138, 2009.

[71] R. Pattarini, R. J. Smeyne, and J. I. Morgan, "Temporal mRNA profiles of inflammatory mediators in the murine 1-methyl-4-phenyl-1,2,3,6-tetrahydropyrimidine model of Parkinson's disease," Neuroscience, vol. 145, no. 2, pp. 654668, 2007.

[72] M. Vila, V. Jackson-Lewis, C. Guégan et al., "The role of glial cells in Parkinson's disease," Current Opinion in Neurology, vol. 14, no. 4, pp. 483-489, 2001.

[73] L. Qin, X. Wu, M. L. Block et al., "Systemic LPS causes chronic neuroinflammation and progressive neurodegeneration," GLIA, vol. 55, no. 5, pp. 453-462, 2007.

[74] A. L. De Lella Ezcurra, M. Chertoff, C. Ferrari, M. Graciarena, and F. Pitossi, "Chronic expression of low levels of tumor necrosis factor- $\alpha$ in the substantia nigra elicits progressive neurodegeneration, delayed motor symptoms and microglia/macrophage activation," Neurobiology of Disease, vol. 37, no. 3, pp. 630-640, 2010.

[75] A. M. Floden, S. Li, and C. K. Combs, “ $\beta$-Amyloid-stimulated microglia induce neuron death via synergistic stimulation of tumor necrosis factor $\alpha$ and NMDA receptors," Journal of Neuroscience, vol. 25, no. 10, pp. 2566-2575, 2005.

[76] A. D. Reynolds, D. K. Stone, J. A. L. Hutter, E. J. Benner, R. L. Mosley, and H. E. Gendelman, "Regulatory T cells attenuate Th17 cell-mediated nigrostriatal dopaminergic 
neurodegeneration in a model of Parkinson's disease," Journal of Immunology, vol. 184, no. 5, pp. 2261-2271, 2010.

[77] H. Wilms, P. Rosenstiel, J. Sievers, G. Deuschl, L. Zecca, and R. Lucius, "Activation of microglia by human neuromelanin is NF-kappaB dependent and involves p38 mitogen-activated protein kinase: implications for Parkinson's disease," The FASEB Journal, vol. 17, no. 3, pp. 500-502, 2003.

[78] W. Zhang, T. Wang, Z. Pei et al., "Aggregated $\alpha$-synuclein activates microglia: a process leading to disease progression in Parkinson's disease," FASEB Journal, vol. 19, no. 6, pp. 533542, 2005.

[79] F. Cicchetti, A. L. Brownell, K. Williams, Y. I. Chen, E. Livni, and O. Isacson, "Neuroinflammation of the nigrostriatal pathway during progressive 6-OHDA dopamine degeneration in rats monitored by immunohistochemistry and PET imaging," European Journal of Neuroscience, vol. 15, no. 6, pp. 991-998, 2002.

[80] A. Członkowska, M. Kohutnicka, I. Kurkowska-Jastrzebska, and A. Członkowski, "Microglial reaction in MPTP (1methyl-4-phenyl-1,2,3,6-tetrahydropyridine) induced Parkinson's disease mice model," Neurodegeneration, vol. 5, no. 2, pp. 137-143, 1996.

[81] M. Kohutnicka, E. Lewandowska, I. Kurkowska-Jastrzebska, A. Członkowski, and A. Członkowska, "Microglial and astrocytic involvement in a murine model of Parkinson's disease induced by 1-methyl-4-phenyl-1,2,3,6-tetrahydropyridine (MPTP)," Immunopharmacology, vol. 39, no. 3, pp. 167-180, 1998.

[82] G. T. Liberatore, V. Jackson-Lewis, S. Vukosavic et al., "Inducible nitric oxide synthase stimulates dopaminergic neurodegeneration in the MPTP model of Parkinson disease," Nature Medicine, vol. 5, no. 12, pp. 1403-1409, 1999.

[83] K. Sriram, J. M. Matheson, S. A. Benkovic, D. B. Miller, M. I. Luster, and J. P. O'Callaghan, "Deficiency of TNF receptors suppresses microglial activation and alters the susceptibility of brain regions to MPTP-induced neurotoxicity: role of TNF- $\alpha$," FASEB Journal, vol. 20, no. 6, pp. 670-682, 2006.

[84] L. P. Quinn, B. Crook, M. E. Hows et al., "The PPAR $\gamma$ agonist pioglitazone is effective in the MPTP mouse model of Parkinson's disease through inhibition of monoamine oxidase B," British Journal of Pharmacology, vol. 154, no. 1, pp. 226-233, 2008.

[85] E. Esposito, V. Di Matteo, A. Benigno, M. Pierucci, G. Crescimanno, and G. Di Giovanni, "Non-steroidal antiinflammatory drugs in Parkinson's disease," Experimental Neurology, vol. 205, no. 2, pp. 295-312, 2007.

[86] B. Xing, M. Liu, and G. Bing, "Neuroprotection with pioglitazone against LPS insult on dopaminergic neurons may be associated with its inhibition of NF- $\kappa \mathrm{B}$ and JNK activation and suppression of COX-2 activity," Journal of Neuroimmunology, vol. 192, no. 1-2, pp. 89-98, 2007.

[87] B. Xing, T. Xin, R. L. Hunter, and G. Bing, "Pioglitazone inhibition of lipopolysaccharide-induced nitric oxide synthase is associated with altered activity of p38 MAP kinase and PI3K/Akt," Journal of Neuroinflammation, vol. 5, article 4, 2008.

[88] A. Bernardo and L. Minghetti, "PPAR- $\gamma$ agonists as regulators of microglial activation and brain inflammation," Current Pharmaceutical Design, vol. 12, no. 1, pp. 93-109, 2006.

[89] T. Koppal, T. V. Petrova, and L. J. Van Eldik, "Cyclopentenone prostaglandin 15 -deoxy- $\Delta$-prostaglandin $\mathrm{J}$ acts as a general inhibitor of inflammatory responses in activated BV2 microglial cells," Brain Research, vol. 867, no. 1-2, pp. 115$121,2000$.
[90] R. Luna-Medina, M. Cortes-Canteli, M. Alonso, A. Santos, A. Martínez, and A. Perez-Castillo, "Regulation of inflammatory response in neural cells in vitro by thiadiazolidinones derivatives through peroxisome proliferator-activated receptor $\gamma$ activation," Journal of Biological Chemistry, vol. 280, no. 22, pp. 21453-21462, 2005.

[91] J. Xu and P. D. Drew, "Peroxisome proliferator-activated receptor- $\gamma$ agonists suppress the production of IL-12 family cytokines by activated glia," Journal of Immunology, vol. 178, no. 3, pp. 1904-1913, 2007.

[92] D. J. Loane, B. F. Deighan, R. M. Clarke, R. J. Griffin, A. M. Lynch, and M. A. Lynch, "Interleukin-4 mediates the neuroprotective effects of rosiglitazone in the aged brain," Neurobiology of Aging, vol. 30, no. 6, pp. 920-931, 2009.

[93] A. Patzer, YI. Zhao, I. Stöck, P. Gohlke, T. Herdegen, and J. Culman, "Peroxisome proliferator-activated receptors $\gamma$ $(\operatorname{PPAR} \gamma)$ differently modulate the interleukin-6 expression in the peri-infarct cortical tissue in the acute and delayed phases of cerebral ischaemia," European Journal of Neuroscience, vol. 28, no. 9, pp. 1786-1794, 2008.

[94] M. P. Pereira, O. Hurtado, A. Cárdenas et al., "Rosiglitazone and 15-deoxy- $\Delta 12$, 14-prostaglandin $\mathrm{J} 2$ cause potent neuroprotection after experimental stroke through noncompletely overlapping mechanisms," Journal of Cerebral Blood Flow and Metabolism, vol. 26, no. 2, pp. 218-229, 2006.

[95] S. Sundararajan, J. L. Gamboa, N. A. Victor, E. W. Wanderi, W. D. Lust, and G. E. Landreth, "Peroxisome proliferatoractivated receptor- $\gamma$ ligands reduce inflammation and infarction size in transient focal ischemia," Neuroscience, vol. 130, no. 3, pp. 685-696, 2005.

[96] C. K. Combs, D. E. Johnson, J. C. Karlo, S. B. Cannady, and G. E. Landreth, "Inflammatory mechanisms in Alzheimer's disease: inhibition of beta-amyloid-stimulated proinflammatory responses and neurotoxicity by PPARgamma agonists," The Journal of Neuroscience, vol. 20, no. 2, pp. 558-567, 2000.

[97] B. Desvergne and W. Wahli, "Peroxisome proliferatoractivated receptors: nuclear control of metabolism," Endocrine Reviews, vol. 20, no. 5, pp. 649-688, 1999.

[98] C. Qi, Y. Zhu, and J. K. Reddy, "Peroxisome proliferatoractivated receptors, coactivators, and downstream targets," Cell Biochemistry and Biophysics, vol. 32, pp. 187-204, 2000.

[99] S. van Neerven and J. Mey, "RAR/RXR and PPAR/RXR signaling in spinal cord injury," PPAR Research, vol. 2007, Article ID 29275, 2007.

[100] D. S. Straus and C. K. Glass, "Cyclopentenone prostaglandins: new insights on biological activities and cellular targets," Medicinal Research Reviews, vol. 21, no. 3, pp. 185210, 2001.

[101] M. Ricote and C. K. Glass, "PPARs and molecular mechanisms of transrepression," Biochimica et Biophysica Acta, vol. 1771, no. 8, pp. 926-935, 2007.

[102] H. L. Zhang, Z. L. Gu, S. I. Savitz, F. Han, K. Fukunaga, and Z. H. Qin, "Neuroprotective effects of prostaglandin $A$ in rat models of permanent focal cerebral ischemia are associated with nuclear factor- $\kappa \mathrm{B}$ inhibition and peroxisome proliferator-activated receptor- $\gamma$ up-regulation," Journal of Neuroscience Research, vol. 86, no. 5, pp. 1132-1141, 2008.

[103] G. Pascual, A. L. Fong, S. Ogawa et al., "A SUMOylationdependent pathway mediates transrepression of inflammatory response genes by PPAR- $\gamma$," Nature, vol. 437, no. 7059, pp. 759-763, 2005.

[104] P. L. McGeer, S. Itagaki, B. E. Boyes, and E. G. McGeer, "Reactive microglia are positive for HLA-DR in the substantia nigra 
of Parkinson's and Alzheimer's disease brains," Neurology, vol. 38, no. 8, pp. 1285-1291, 1988.

[105] T. Yamada, P. L. McGeer, and E. G. McGeer, "Lewy bodies in Parkinson's disease are recognized by antibodies to complement proteins," Acta Neuropathologica, vol. 84, no. 1, pp. 100-104, 1992.

[106] C. F. Orr, D. B. Rowe, Y. Mizuno, H. Mori, and G. M. Halliday, "A possible role for humoral immunity in the pathogenesis of Parkinson's disease," Brain, vol. 128, no. 11, pp. 2665-2674, 2005.

[107] V. Brochard, B. Combadière, A. Prigent et al., "Infiltration of CD4+ lymphocytes into the brain contributes to neurodegeneration in a mouse model of Parkinson disease," Journal of Clinical Investigation, vol. 119, no. 1, pp. 182-192, 2009.

[108] K. Hisanaga, M. Asagi, Y. Itoyama, and Y. Iwasaki, "Increase in peripheral CD4+ bright CD8 dull+ $\mathrm{T}$ cells in Parkinson disease," Archives of Neurology, vol. 58, no. 10, pp. 1580-1583, 2001.

[109] Y. Baba, A. Kuroiwa, R. J. Uitti, Z. K. Wszolek, and T. Yamada, "Alterations of T-lymphocyte populations in Parkinson disease," Parkinsonism and Related Disorders, vol. 11, no. 8, pp. 493-498, 2005.

[110] M. Reale, C. Iarlori, A. Thomas et al., "Peripheral cytokines profile in Parkinson's disease," Brain, Behavior, and Immunity, vol. 23, no. 1, pp. 55-63, 2009.

[111] G. Stypuła, J. Kunert-Radek, H. Stepień, K. Zylińska, and M. Pawlikowski, "Evaluation of interleukins, ACTH, cortisol and prolactin concentrations in the blood of patients with Parkinson's disease," NeuroImmunoModulation, vol. 3, no. 23, pp. 131-134, 1996.

[112] YI. He, W. D. Le, and S. H. Appel, "Role of Fcy receptors in nigral cell injury induced by Parkinson disease immunoglobulin injection into mouse substantia Nigra," Experimental Neurology, vol. 176, no. 2, pp. 322-327, 2002.

[113] A. D. Reynolds, R. Banerjee, J. Liu, H. E. Gendelman, and R. L. Mosley, "Neuroprotective activities of CD4+CD25+ regulatory T cells in an animal model of Parkinson's disease," Journal of Leukocyte Biology, vol. 82, no. 5, pp. 1083-1094, 2007.

[114] A. D. Reynolds, D. K. Stone, R. L. Mosley, and H. E. Gendelman, "Nitrated $\alpha$-synuclein-induced alterations in microglial immunity are regulated by CD4+ T cell subsets," Journal of Immunology, vol. 182, no. 7, pp. 4137-4149, 2009.

[115] M. Ricote, J. S. Welch, and C. K. Glass, "Regulation of macrophage gene expression by the peroxisome proliferatoractivated receptor- $\boldsymbol{\gamma}$," Hormone Research, vol. 54, no. 5-6, pp. 275-280, 2000.

[116] R. B. Clark, D. Bishop-Bailey, T. Estrada-Hernandez, T. Hla, L. Puddington, and S. J. Padula, "The nuclear receptor PPAR $\gamma$ and immunoregulation: PPAR $\gamma$ mediates inhibition of helper T cell responses," Journal of Immunology, vol. 164, no. 3, pp. 1364-1371, 2000.

[117] C. K. Glass and K. Saijo, "Nuclear receptor transrepression pathways that regulate inflammation in macrophages and $\mathrm{T}$ cells," Nature Reviews Immunology, vol. 10, no. 5, pp. 365376, 2010.

[118] H. Y. Won, H. J. Min, W. H. Lee, S. G. Kim, and E. S. Hwang, "G $\alpha 12$ is critical for TCR-induced IL-2 production and differentiation of T helper 2 and T helper 17 cells," Biochemical and Biophysical Research Communications, vol. 394, no. 3, pp. 811-816, 2010.

[119] L. Klotz, S. Burgdorf, I. Dani et al., "The nuclear receptor PPAR $y$ selectively inhibits Th17 differentiation in a T cellintrinsic fashion and suppresses CNS autoimmunity," Journal of Experimental Medicine, vol. 206, no. 10, pp. 2079-2089, 2009.

[120] A. Awasthi and V. K. Kuchroo, "T17 cells: from precursors to players in inflammation and infection," International Immunology, vol. 21, no. 5, pp. 489-498, 2009.

[121] A. P. Woster and C. K. Combs, "Differential ability of a thiazolidinedione PPAR $y$ agonist to attenuate cytokine secretion in primary microglia and macrophage-like cells," Journal of Neurochemistry, vol. 103, no. 1, pp. 67-76, 2007.

[122] M. A. Bouhlel, B. Derudas, E. Rigamonti et al., "PPAR $\gamma$ activation primes human monocytes into alternative M2 macrophages with anti-inflammatory properties," Cell Metabolism, vol. 6, no. 2, pp. 137-143, 2007.

[123] M. A. Bouhlel, J. Brozek, B. Derudas et al., "Unlike PPAR $\gamma$, $\operatorname{PPAR} \alpha$ or $\operatorname{PPAR} \beta / \delta$ activation does not promote human monocyte differentiation toward alternative macrophages," Biochemical and Biophysical Research Communications, vol. 386, no. 3, pp. 459-462, 2009.

[124] F. Lovren, Y. Pan, A. Quan et al., "Adiponectin primes human monocytes into alternative anti-inflammatory M2 macrophages," American Journal of Physiology, vol. 299, no. 3, pp. H656-H663, 2010. 


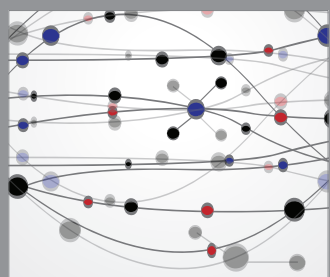

The Scientific World Journal
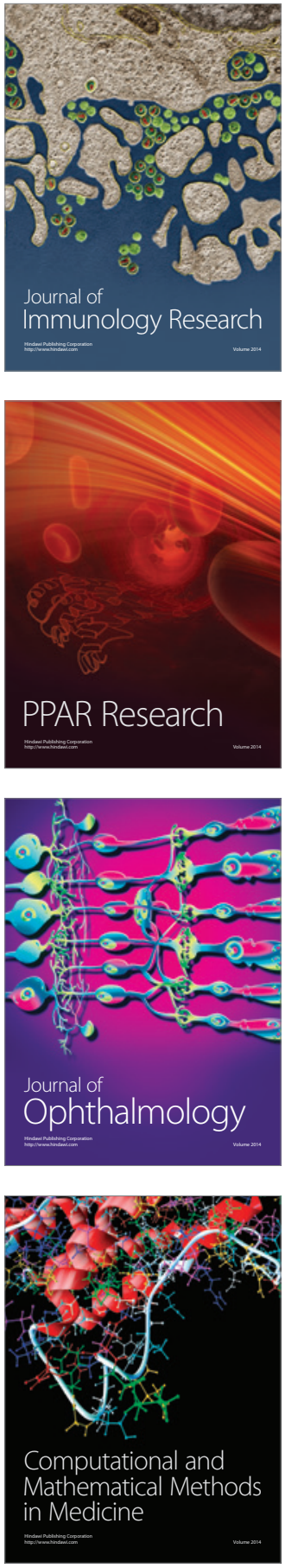

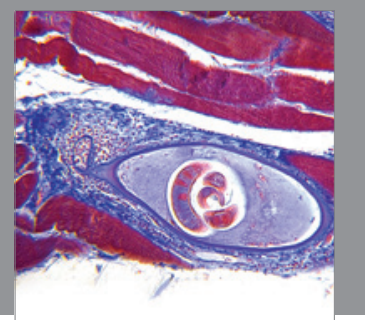

Gastroenterology

Research and Practice
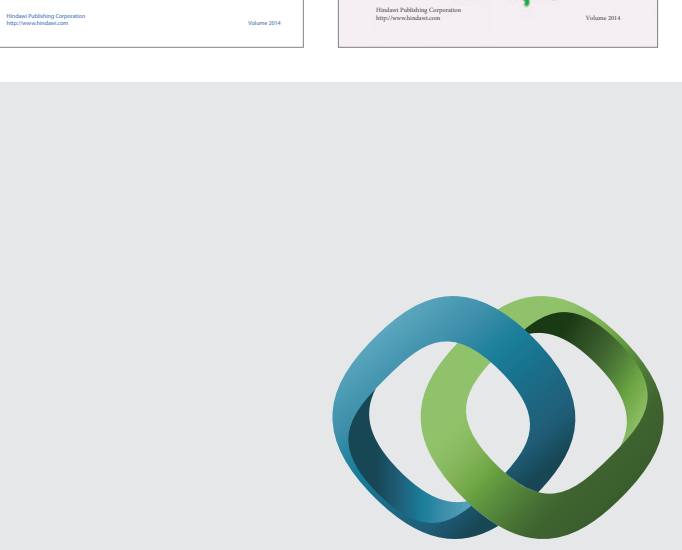

\section{Hindawi}

Submit your manuscripts at

http://www.hindawi.com
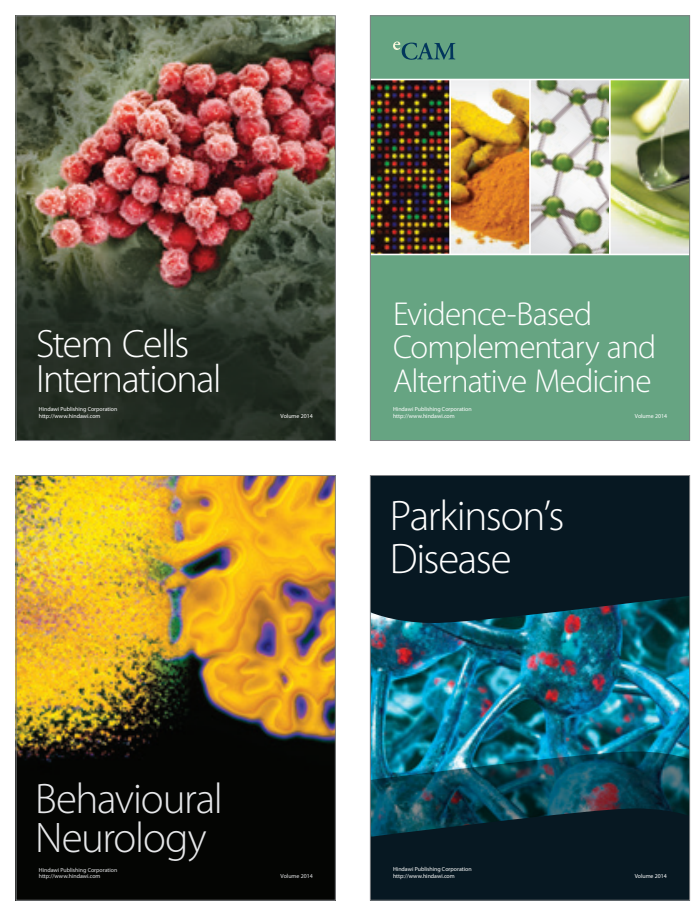

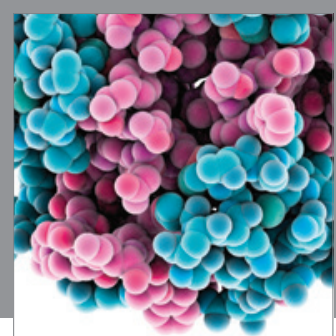

Journal of
Diabetes Research

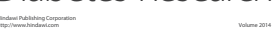

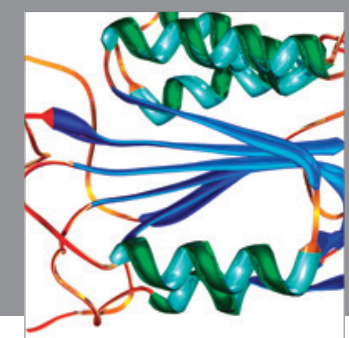

Disease Markers
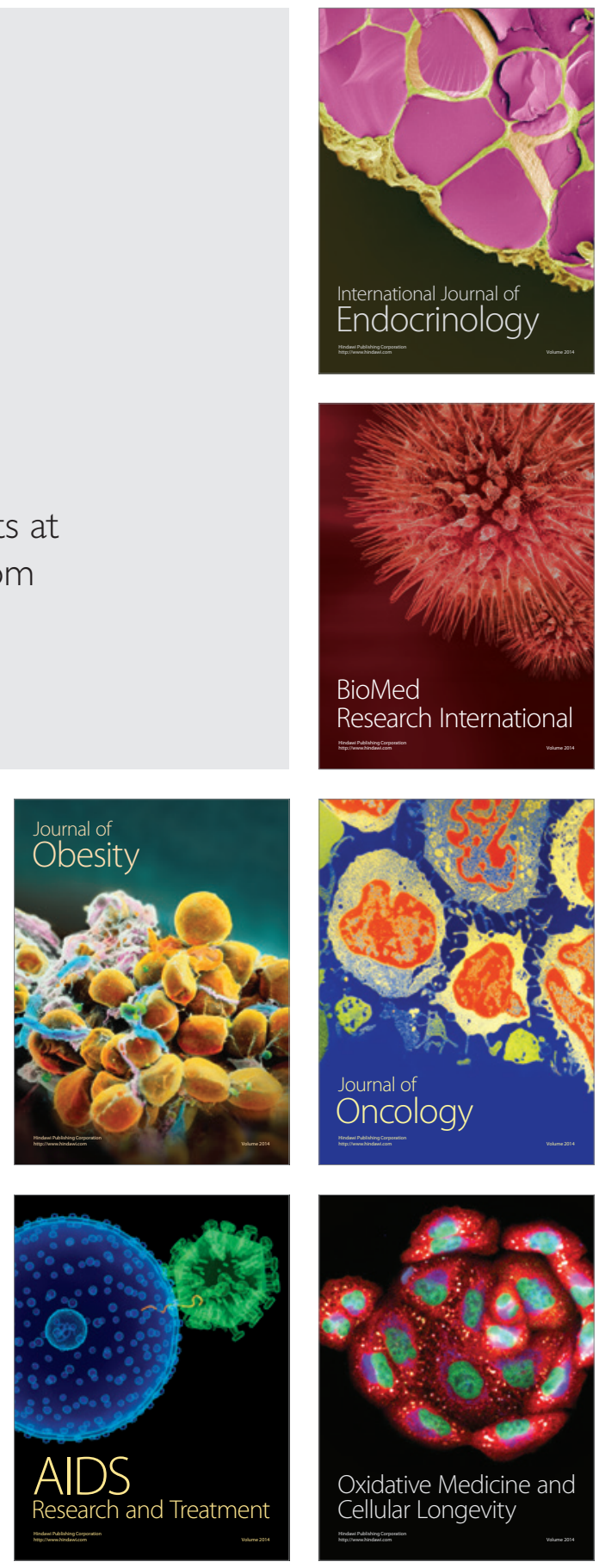